\title{
The Carbonation Model of Concrete Structures and Its Application
}

\author{
Junting Jiao ${ }^{1, a^{*}}$, Bo Diao ${ }^{2, b}$ and Chenfei Wang ${ }^{1, c}$ \\ ${ }^{1}$ School of Civil Engineering and Architecture, Xiamen University of Technology, Xiamen 361024, \\ Fujian, China \\ ${ }^{2}$ Department of Airport and Road Engineering, Bei Hang University, Beijing 100191, China

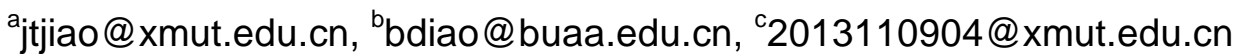

Keywords: $\mathrm{CO}_{2}$ concentration, Concrete remembers, Carbonation time-variant mode.

Abstract. Carbonization is one of the main factors affecting the durability of concrete structures in atmospheric environment. According to the theory of reliability and the climate forecast data, using the concrete carbonation prediction model improved, the time-dependent reliability of concrete structures were researched, for three environmental classes of I environment in china Code for durability of concrete structures. The study results showed: (1) In this paper, the results of the improved concrete carbonation prediction model was in good agreement with those of other reference's concrete carbonation prediction models. (2) When the carbonation emission scenarios would make $\mathrm{CO}_{2}$ concentration to be higher, then this would lead to the carbonation depth in concrete cover and cumulative failure probability to increase more. But the carbonation depth in concrete cover and cumulative failure probability would decrease more when environmental effect being more serious; for concrete carbonation development was delayed by raising the concrete minimum strength, increasing concrete cover depth, and decreasing concrete Maximum water cement ratio. (3) Improving the concrete strength and the concrete cover depth should be done in future concrete structures design to improve the concrete carbonation resistance and concrete structures durability.

\section{Introduction}

Concrete carbonation is the main cause of the durability and service life for reinforced concrete (RC) structures in atmospheric environment. Carbonation of concrete is a complex physical and chemical process, which are affected by the working environment (such as temperature, relative humidity and $\mathrm{CO}_{2}$ concentration, the load and so on) and concrete material properties (such as water cement ratio, cement content, compressive strength and the cover thickness). Now in the world on the concrete carbonization mechanism and its influencing factors have been investigated deeply. from different angles, the researchers have proposed some various carbonization prediction models, including the early theoretical model [1], experience model [2-4], based on theory and experiment of the pracyical model based on theory and experiment [5] and the stochastic model [6-10] ect. Due to the diversity of influencing factors, the complexity of the environmental conditions, material property discrete, and the uncertainty of other influence factors for concrete carbonation; there is no the practical calculation model which had the adequate theoretical basis and the comprehensive consideration of various affecting factors [11]. So then we still need to continue exploring in order to suggest a more scientific, reasonable and practical model of concrete carbonation.

With the rapid development of the global economy, the climate is changing, and the concentration of $\mathrm{CO}_{2}$ is increasing continuously in the atmosphere. The Intergovernmental Panel on Climate Change (IPCC) fourth 2007 Climate Research Report has given: In the end of 2000, the global atmospheric $\mathrm{CO}_{2}$ concentration increased to about $365 \mathrm{ppm}$; and predicted that the atmospheric $\mathrm{CO}_{2}$ concentration would exceed $1000 \mathrm{ppm}$ in the end of 2100 [12]. In recent years, the influence of concrete carbonization from climate change (such as $\mathrm{CO}_{2}$ concentration, temperature, etc.) has been studied by [8-10, 13]. Yoon et al. studied the effect of atmospheric $\mathrm{CO}_{2}$ concentration on concrete carbonation, and proposed the carbonation prediction model h based on the first law of Fick in 2007 [8]. Jian Xin Peng et al. proposed carbonation model considering the uncertainty of $\mathrm{CO}_{2}$ concentration based on the Yoon carbonation model, then studied the influence on concrete carbonation form the high, medium 
and low three carbon emission scenarios according to the fourth IPCC climate research report data in 2010 [9]. Stewart et al. improved the Yoon model, suggested the carbonation $\mathrm{CO}_{2}$ volume integral correction considering climate change, and researched the effect on Australian concrete carbonation, the durability form the increased $\mathrm{CO}_{2}$ concentration and the increased temperature on the basis of climate forecasting data in 2011 [10]. Xie Huibing et al. used Stewart's model method, and researched the carbonation depth and reliability index of RC structures designed by China concrete structure durability specification [14] with 100 years service life according to the carbon emissions prediction data of the IPCC Fourth Climate Research Report in 2015. These study results showed that the increaseing $\mathrm{CO}_{2}$ concentration and the elevated temperature in the future climate would have the effects on RC carbonation, and this should not be ignored. Fick's first law is the theoretical foundation of carbonation model in the reference [8-10, 13]; and the model parameters are more, which are not easy to measure.

Based on the Niu Ditao's concrete carbonation model [6], this paper propose a improved concrete carbonation model, which consider the dependent time and the uncertainty of $\mathrm{CO}_{2}$ concentration. Then according to the carbon emissions prediction data of the IPCC Fourth Climate Research Report, the effect from $\mathrm{CO}_{2}$ concentration changing are researched on the carbonation and durability of $\mathrm{RC}$ strctures in China.

\section{Carbonation Prediction Model}

The Niu Ditao's concrete carbonation model [6] is easy to get the parameters, considers the random of the parameter variables in the process of calculation, thenthe calculated results are in good agreement with the measured values. But the $\mathrm{CO}_{2}$ concentration in the model is constant, which can not be changed with the time and the uncertainty of the $\mathrm{CO}_{2}$ concentration in the atmosphere. So one carbonation model is improved in this paper, and it is presented as follow:

$$
x_{c(t)}=2.56 \mathrm{~K}_{\mathrm{mc}} \mathrm{k}_{\mathrm{j}} \sqrt{K_{\mathrm{CO}_{2}} \frac{C_{\mathrm{CO}_{2}(t)}}{C_{\mathrm{CO}_{2}(0)}}} \mathrm{k}_{\mathrm{p}} \mathrm{k}_{\mathrm{s}} \sqrt[4]{T}(1-R H) R H\left(\frac{57.94}{f_{c u}} m_{c}-0.76\right) \sqrt{t}
$$

Where $x_{\mathrm{c}(\mathrm{t})}$ is the concrete carbonation depth at time $\mathrm{t}, / \mathrm{mm} ; t$ is the concrete time $\mathrm{t}$, /year; $\mathrm{K}_{\mathrm{mc}}$ is the uncertainty of calculation model, a random variable with mean $=0.996$ and standard deviation $=0.355$; $C_{\mathrm{co} 2(t)}$ is the time-varying mean function of $\mathrm{CO}_{2}$ concentration( form Fig.1 ), the unit needs to be converted to volume concentration, namely: $\times 10^{-6}$; $K_{\mathrm{CO} 2}$ is the $\mathrm{CO}_{2}$ concentration uncertainty, a random variable with mean $=1.0$, standard deviation (according to Fig.1); $C_{\mathrm{CO} 2(0)}$ is that the average concentration of $\mathrm{CO}_{2}$ at the beginning of carbonization, and the unit is the volume concentration; Other parameters are the same with those in references [6].

\section{Comparison between Carbonation Prediction Models}

In order to verify the effectiveness of the improved model proposed in this paper, one $\mathrm{RC}$ member is calculated. For the RC member, cover thickness mean

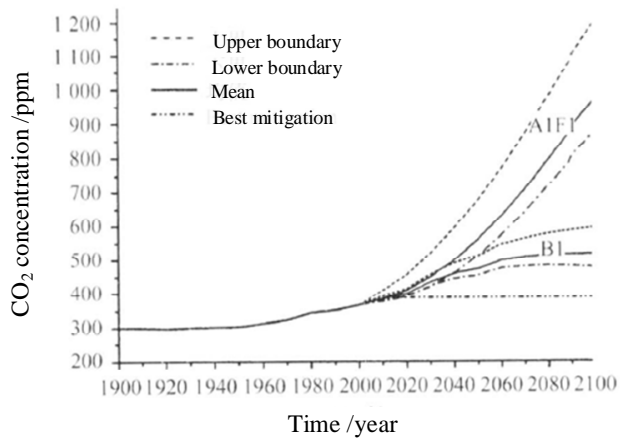

Fig. 1 The $\mathrm{CO}_{2}$ concentration time-dependent prediction data of three carbonation emission ${ }^{[12]}$ is $20 \mathrm{~mm}$, its variation coefficient of is 0.1 ; Water cement ratio is 0.5 ; Concrete strength grade is $\mathrm{C} 30$, $\mathrm{fc}_{\mathrm{uk}}$ mean $=30 \mathrm{Mpa}$, its variation coefficient is 0.12 ; Ambient temperature $\mathrm{T}=20{ }^{\circ} \mathrm{C}$, relative humidity $\mathrm{RH}=75 \% ; k_{\mathrm{j}}=1, k_{\mathrm{p}}=1, k_{\mathrm{s}}=1.2, C_{\mathrm{CO} 2(0)}$ is measured in Fig. 1 in 2015: $390 \times 10^{-6}$.

Comparison of Calculation results of the models between in this paper in Literatures [8-10]. A $\mathrm{s}$ shown in Fig.2, the calculation results of the improved concrete carbonation model are presented in this paper. The results are in good agreement with those of the models in the literatures [8] - [10]. 


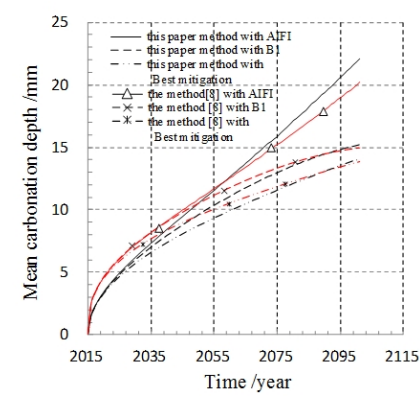

(a) The comparison between this paper and literature [8]

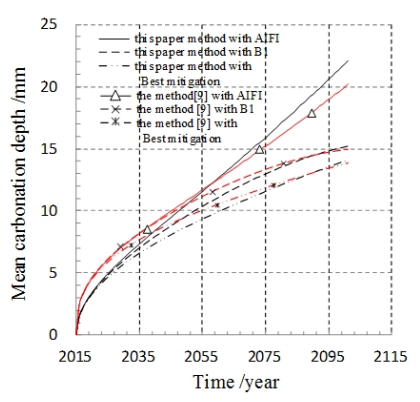

(b) The comparison between this paper and literature [9]

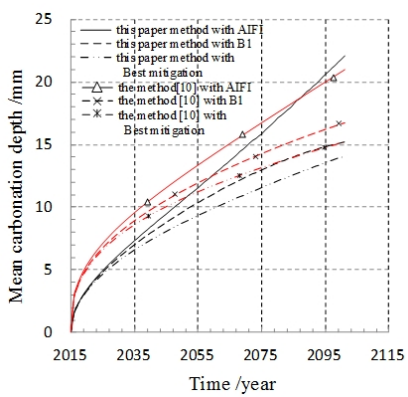

(c) The comparison between this paper and literature [10]

Fig.2 The comparison of the calculation results between concrete carbonation models

Comparison of Calculation results of the models between in this paper in Literatures [6]. As shown in Fig.3, the carbonation depths of literature [6] model are the same with A1FI, B1and Best mit igation carbon emission. The reason is the constant coefficient $\mathrm{CO}_{2}$ in literature [6] model; and the ti me variability of $\mathrm{CO}_{2}$ concentration can't be reflected with future climate changing. In the early carb onization time when $\mathrm{CO}_{2}$ concentration variation is not obvious, the calculation result of this paper $\mathrm{m}$ odel is in agreement with that of literature [6] model. In the mi $\mathrm{d}$ and late carbonation time with $\mathrm{CO}_{2}$ concentration changing more and more, this paper model calculation result could reflec $\mathrm{t}$ the effe-ct on carbonization form $\mathrm{CO}_{2}$ concentration variation.

\section{Carbonation Reliability Analysis}

Carbonation Cumulative Failure Probability. Commonly f or RC structures in the atmosphere, the concrete carbonation depth is considered as the load effect $\mathrm{S}$, the concrete cover thi ckness as structure resistance R. So the function is as followin $\mathrm{g}$ in the normal use limit state:

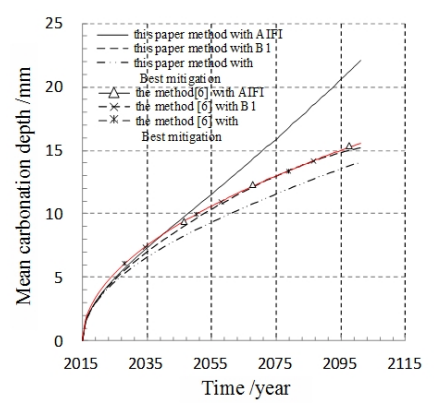

Fig.3 The calculation result comparison between this paper and reference [6] $Z=R-S=C-x_{c(t)}$

Where $\mathrm{Z}$ is the time-varying function; $\mathrm{C}$ is the concrete cover thickness, $/ \mathrm{mm} ; x_{\mathrm{c}(\mathrm{t})}$ is calculated by Eq. (1).

Calculating Carbonation Cumulative Failure Probability. The carbonation cumulative failure pro bability would be calculated By Eq. (1) and Eq. (3). Due to the random and variability of parameter-s, such as the protective layer thickness, concrete strength, $\mathrm{k}_{\mathrm{CO} 2}$ and $\mathrm{k}_{\mathrm{mc}}$, Monte-Carlo method (MC me thod) is adopted, sampling number $n=10^{5}$.

\section{Engineering Applications}

The Durability Code of Concrete Structures in China. The durability design code of concrete str uctures [14] was promulgated in 2008, and the design code of concrete structures [15] was promulga ted in 2010. The two codes had the durability design specification of concrete structures. In literature [14], Environment I refers to the deterioration caused by concrete carbonation and the structure dura bility reducing. Environment I is divided into three grade: I-A (minor environmental effects), I-B (mil $\mathrm{d}$ environmental effects), I-C (moderate environmental effects); and the special technical requirement $\mathrm{s}$ are seen in table 1 about service life, the minimum strength and maximum water cement ratio an 
$\mathrm{d}$ the minimum cover thickness. In this paper, the technical requirements of RC durability design are calculated according to literature [14].

Random Variables and Other Parameters. In th is paper, the statistical parameters, $\mathrm{K}_{\mathrm{mc}}, f_{\mathrm{cu}}, K_{\mathrm{CO} 2}$ a nd $\mathrm{c}$ are the random variables, as shown in table 2. The other parameters are: $\mathrm{T}=20{ }^{\circ} \mathrm{C}, \mathrm{RH}=75 \%, \mathrm{k}_{\mathrm{j}}$ $=1, \mathrm{k}_{\mathrm{p}}==1, \mathrm{k}_{\mathrm{s}}==1.2, C_{\mathrm{CO} 2(0)}$ is measured in Fig. 1 in 2015: $390 \times 10^{-6}$.

Calculation Result Analysis. In order to the effect $\mathrm{s}$ on carbonation of reinforced concrete structure fo rm different carbon emission scenarios, A1fI, B1, a nd Best mitigation emission scenarios are calculated from 2015 to 2100 year. The 2015-year level carbo $\mathrm{n}$ emissions is assumed as the standard carbonation. The carbonization of A1fI, B1 and Best mitigation emissions were compared with the standard carbon ation; then the carbonation reliability are analyzed, according to Environment I [14].

Mean Carbonation Depth Corresponding to Different Carbon Emission. Fig. 4 shows the aver age carbonation depth of three different carbon emission scenarios, A1fI, B1, and Best mitigation emi ssions for 100 year service life, corresponding to the three grades of Environment I class. From the Fi g.4, (1) for A1FI, B1 and Best mitigation carbon emissions, the average carbonation depth is: A1FI $>\mathrm{B}$ $1>$ Best mitigation. The reason is that $\mathrm{CO}_{2}$ concentration is more high to cause average carbonation $\mathrm{d}$ epth more large; and the corresponding $\mathrm{CO}_{2}$ concentration forecast data is $\mathrm{A} 1 \mathrm{FI}>\mathrm{B} 1>\mathrm{Best}$ mitigation for the three carbon emissions. (2) The effective technical measures, for example raising minimum co ncrete strength and increasing minimum concrete cover thickness, and reducing maximum water ceme nt ratio, the concrete carbonation depth could be decreased with the environment grade increase-ing.

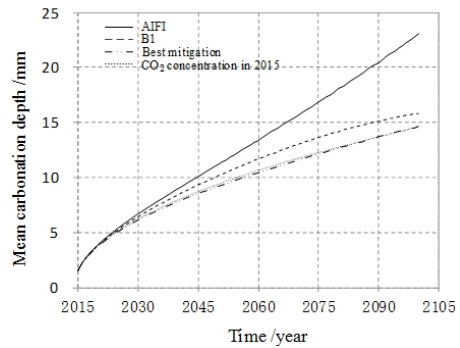

(a) I-A

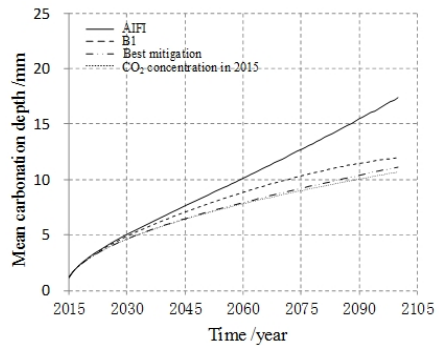

(b) I-B

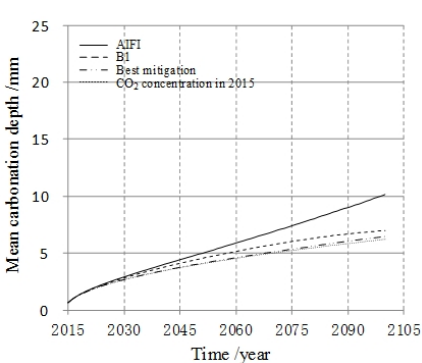

(c) $\mathrm{I}-\mathrm{C}$

Fig.4 The mean carbonation depth of I environment with different carbonation emission for 100-year designed service life

Table 3 is the comparison of average carbonation depth between three carbon emission scenarios a nd the standard carbonation level. As shown in Table 3, (1) when $\mathrm{t}=50$ years, the average carbonation depth of A1FI is about $130 \%$ of the standard carbonation level; the average carbonation depth of B1i $\mathrm{s}$ about $110 \%$ of the standard carbonation level; and the average carbonation depth of Best mitigation is the same as that of the standard carbonation level, for its $\mathrm{CO}_{2}$ concentration is close to that of the standard carbonation level. (2) When $\mathrm{t}=86$ years the average carbonation depth of A1FI is about $160 \%$ of the standard carbonation level; the average carbonation depth of B1 is about $120 \%$ of the standard carbonation level; and the average carbonation depth of Best mitigation is the same as that of the sta ndard carbonation level. 
Table 3 The mean carbonation depth comparison

\begin{tabular}{cccccccccc}
\hline $\begin{array}{c}\text { Grad } \\
\mathrm{e}\end{array}$ & $\begin{array}{c}\mathrm{t} \\
\text { /year }\end{array}$ & AIFI & B1 & Best & Base & AIFI/Base & B1/Base & Best/Base & $\begin{array}{c}\text { service life } \\
\text { /year }\end{array}$ \\
\hline I-A & 50 & 14.32 & 12.22 & 10.91 & 11.10 & 1.290 & 1.101 & 0.983 & 100 \\
I-B & 50 & 10.80 & 9.27 & 8.25 & 8.13 & 1.328 & 1.140 & 1.015 & 100 \\
I-C & 50 & 6.28 & 5.39 & 4.79 & 4.73 & 1.326 & 1.138 & 1.013 & 100 \\
I-A & 86 & 23.07 & 15.84 & 14.69 & 14.60 & 1.580 & 1.085 & 1.006 & 100 \\
I-B & 86 & 17.38 & 11.96 & 11.07 & 10.63 & 1.635 & 1.125 & 1.041 & 100 \\
I-C & 86 & 10.13 & 6.95 & 6.44 & 6.18 & 1.639 & 1.124 & 1.042 & 100 \\
\hline
\end{tabular}

Carbonation Cumulative Failure Probability Corresponding to Different Carbon Emission. Fig.5 shows the carbonation cumulative failure probability of three different carbon emission scenario s, A1fI, B1, and Best mitigation emissions for 100 year service life, corresponding to the three grades of Environment I class. According to the Fig.5, (1) for A1FI, B1 and Best mitigation carbon emissions, the carbonation cumulative failure probability is: A1FI $>\mathrm{B} 1>\mathrm{Best}$ mitigation. This shows that the grea ter the $\mathrm{CO} 2$ concentration is, the greater the carbonation cumulative failure probability is, the m-ore obvious the influence on the durability of RC structures is with time increasing. (2) The carbon-ation cumulative failure probability of decrease when environmental grade raises. For some effective techni cal measures are used, such as increasing concrete minimum strength, concrete minimum cover thickn ess, and reducing maximum water cement ratio, then the concrete carbonation process is decreased.

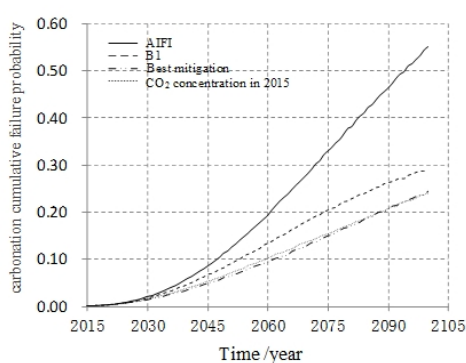

(a) I-A

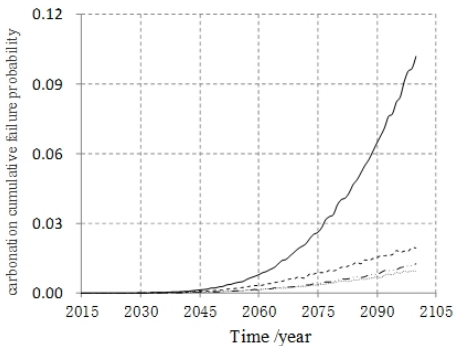

(b) I-B

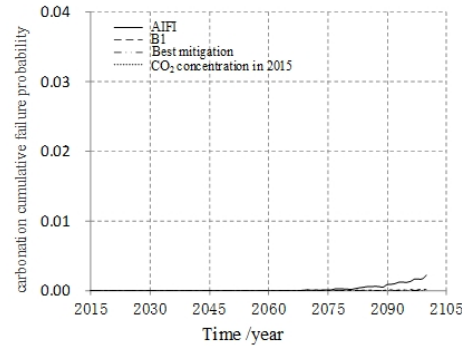

(c) I-C

Fig.5 The carbonation cumulative failure probability of I environment with different carbonation emission for 100-year designed service life

\section{Conclusions}

(i) In this paper, the improved carbonation model is proposed. The comparission of calculation results are done by using the improved model method; and they are in good agreement with those of existing model methods.

(ii) For Environment I [14], A1fI and B1 carbon emission scenarios would cause carbonation depth and carbonization cumulative failure probability to increases; best mitigation of carbon emissions situation is basically not caused by carbonization depth, cumulative failure probability increases; but Best mitigation carbon emission scenario wouldn't lead to the increase of the carbonation depth and the cumulative failure probability. Corresponding to the three carbon emissions, the carbonation depth and cumulative failure probability decreases with the increasing environmental grade, by increasing concrete minimum strength, minimum concrete cover thickness and reducing maximum water cement ratio, and the development of concrete carbonation is delayed.

(iii) According to the global future climate forecast report, the $\mathrm{CO}_{2}$ concentration in the atmosphere would increase, and the durability of RC structures might be affected. In order to ensure the durability of RC structures and improve the concrete resistance carbonization, concrete strength and concrete cover thickness should be increased. 


\section{Acknowledgements}

This work was financially supported by the financial support of the National Natural Science Foundation of China (51178020 and 51478404) and the A Project of Fujian Provincial Education Department (JA14241).

\section{References}

[1] V. C. Papadkis, C. C. Vayenas, M. N. Faradis, Fundamental modeling and experimental investigation of concrete carbonation, ACI Material Journal, 88(1991):363-373.

[2] A. M. Zhu, Concrete carbonation and the durability of reinforced concrete, Concrete, 6(1992):18-22. (in chinese)

[3] L. P. Xu, Sh. Y. Huang, A mathematical model of predicting concrete carbonation depth, Journal of Shanghai Institute of building materials, 4(1991):347-356. (in chinese)

[4] X. Y. Di, Y. Zhou, The study on concrete carbonation, Proceedings of the Fourth National Symposium on concrete durability, 1991.11. (in chinese)

[5] Y. Zhang, L. X. Jiang, A practical mathematical model of concrete carbonation depth based on carbonation mechanism, Industrial buildings, 1(1998):16-19. (in chinese)

[6] N. T. Di, The durability and life prediction of concrete structures, Science Press, Beijing, 2003. (in chinese)

[7] W. J Qu, D. P. Chen, A stochastic model of concrete carbonation, Journal of Tongji University, 5(2007):577-581. (in chinese)

[8] I. S. Yoon, O. Copuroglu, K. B. Park, Effect of Global climatic change on carbonation progress of concrete, Atmospheric Environment, 34(2007): 7274-7285.

[9] J. X. Peng, X. D. Shao, J. R. Zhang, Climate change, $\mathrm{CO}_{2}$ emission scenrios and effects on carbonation-induced cracking and time-dependent reliability of reinforced concrete structures, Chian Civil Engineering Journal, 6(2010):74-81. (in chinese)

[10]M. G. Stewart, X. M. Wang, M. Nguyen, Climate change impact and risks of concrete infrastructure deterioration, Engineering Structures, 4(2011): 1326-1337.

[11] W. L. Jin, X. Y. Zhao, The durability of concrete structures, Science Press, Beijing, 2002. (in chinese)

[12] G. A. Meehl, T. F. Stocker, W. D. Collins, et al, Global climate projections. In: Climate change 2007: The physical science basis [R], Cambridge University, 2007.

[13]H. B. Xie, Y. F. Wang, X. Y. Yang, et al, Influence of climate change on reliability of RC structure under carbonization, Journal of Beijing Jiaotong University, 1(2015): 72-77. (in chinese)

[14] GB/T50476-2008, Code for the durability design of concrete structures, China Architecture \& Building Press, Beijing, 2008. (in chinese)

[15] GB50010-2008, Code for the design of concrete structures, China Architecture \& Building Press, Beijing, 2010. (in chinese)

[15]GB50068-2001, Unified standard for the reliability design of building structures, China Architecture \& Building Press, Beijing, 2001. (in chinese) 